\title{
DENSIMETRIC SEPARATION OF COAL USING MAGNETIC FLUIDS
}

\author{
J. SVOBODA* \\ Advanced Technologies Worldwide, PO Box 73508, Fairland 2030, Johannesburg, South Africa
}

(Received 22 June 2004; In final form 6 October 2004)

\begin{abstract}
Ferrohydrostatic separation of particles in magnetic fluids is a sink-float technique based on generalized Archimedes law whereby, in addition to the conventional force of gravity, a magnetically induced force also acts on the fluid. This additional magnetic pull creates a magnetically induced buoyancy force on a particle immersed in the fluid. This buoyancy force can be accurately controlled over a wide range and particles as dense as $20000 \mathrm{~kg} / \mathrm{m}^{3}$ can be made to float. The selectivity of separation is very high and mixtures of particles with a density differential as small as $30 \mathrm{~kg} / \mathrm{m}^{3}$ can be separated. As a result of the ability of FHS to separate material into narrow, well-defined density fractions, the technique is particularly suitable for densimetric analysis. Sink-float analysis of coal has been one of the areas of potential application of FHS. The cost of heavy liquids used for coal fractionation, and of their subsequent recovery and disposal are considerable and motivation to use FHS has therefore been strong. Numerous laboratory and pilot-plant scale tests have been conducted in this direction, particularly in Eastern Europe and Japan. Investigation of ash and sulphur content, and the mass yield into density fractions, confirmed that heavy liquid and FHS techniques are very similar in their performance. Very selective FHS separators with automated density control have recently been designed and built. A technique for the recovery of ferrofluids has been developed and low-cost ferrofluids are being manufactured on a production scale. Technology for accurate, environmentally friendly hands-off densimetric analysis of coal by is thus available
\end{abstract}

\section{INTRODUCTION}

Separation in magnetic fluids is a sink-float technique of density separation, which relies on selective levitation and sinking of minerals based on their relative densities and that of the separating medium. In this technique a magnetic fluid placed in a non-homogeneous magnetic field exhibits an apparent density different from its natural density. This apparent density can be controlled through a wide range of values, exceeding densities of all known elements and materials. An important feature of this method is the very high selectivity of separation whereby mixtures comprising particles with very small density differential can be separated. Separators with magnetic fluids are used, on an industrial scale, for the recovery of gold and PGMs, and its application to the recycling of electronic and automobile scrap are being explored by several organizations in Europe and Japan. Treatment of base metals, diamond-bearing

*Corresponding author. E-mail: jsvoboda@global.co.za 
minerals and the beneficiation of various process tailings represent a wide field of applications of this unique technique.

As a result of the ability of magnetic fluids to separate materials into narrow, welldefined density fractions in a wide range of densities, not achievable by any other method, the technique is particularly suitable for densimetric analysis. Sink-float analysis of coal has been one of the areas of potential application. Currently, standard densimetric analysis of coal is performed in zinc chloride and bromoform, both being toxic and expensive heavy liquids. The cost of the liquids and of their subsequent recovery and disposal are considerable and the motivation to apply separation in magnetic fluids to the fractionation of coal has therefore been strong. Numerous laboratory explorations have been conducted in this direction, particularly in Eastern Europe and Japan. Comparative investigations of ash and sulphur content, and the mass yield into different density fractions, confirmed that heavy liquid and magnetic fluid techniques are very similar in their performance.

In the following sections the principles of separation in magnetic fluids will be outlined and the future developments and application to coal fractionation will be discussed.

\section{CONCEPT OF SEPARATION IN MAGNETIC FLUIDS}

\subsection{General Considerations}

A schematic diagram of the concept of separation in magnetic fluids is shown in Fig. 1. Permanent magnets or electromagnets generate a non-homogeneous magnetic field in the separation gap. The desired pattern of the magnetic field is achieved by shaping the pole tips. A separation chamber placed between the pole-pieces of the magnetic circuit is filled with a magnetic fluid.

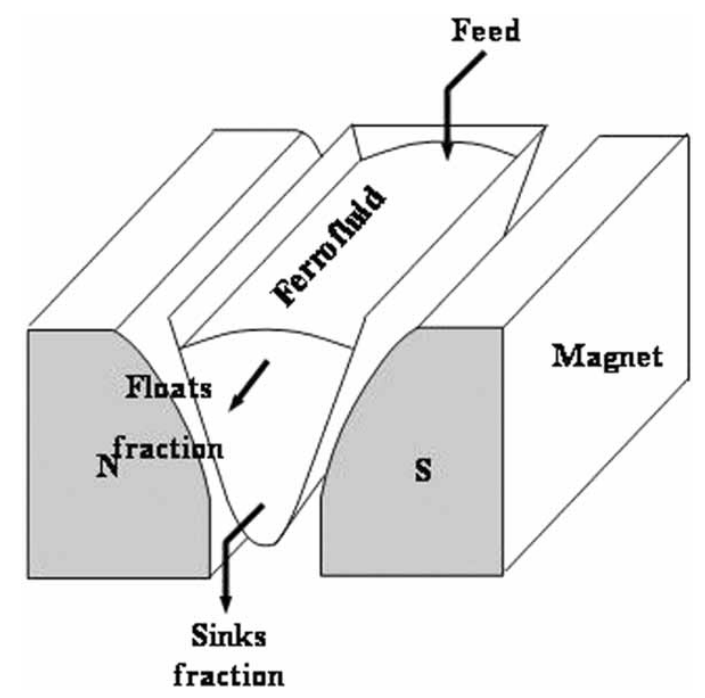

FIGURE 1 The concept of separation with magnetic fluids. 


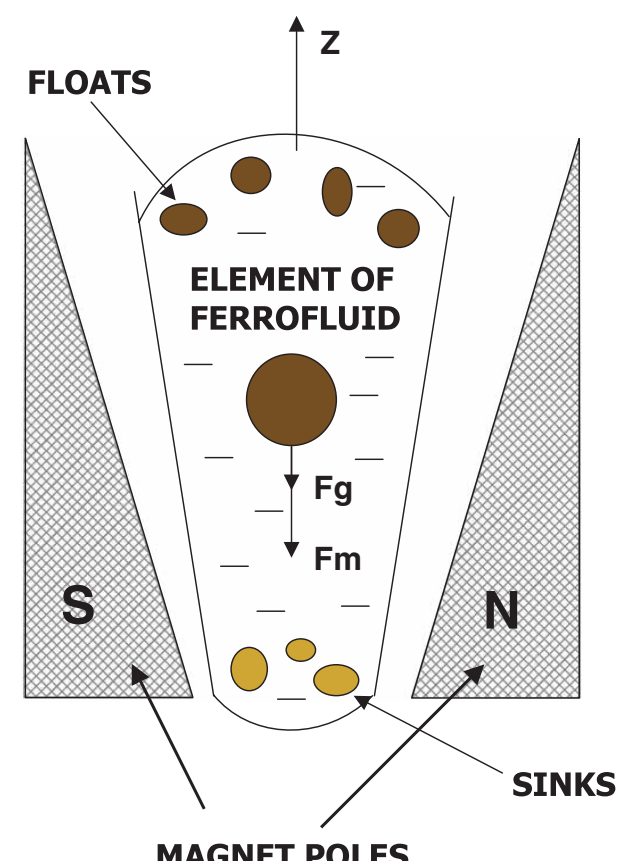

FIGURE 2 Schematic diagram of the process of separation in magnetic fluids.

The dry material, from which strongly magnetic particles were removed, is fed into the fluid. Several forces act upon a particle suspended in the fluid and the balance of these forces with respect to the apparent density of the fluid will determine the behaviour of the particle. Fig. 2 schematically describes the process of separation.

There are two fundamental forces that act on a given volume of the magnetic fluid, namely the force of gravity and the magnetic traction force. The total force on the magnetic fluid of volume $V_{f}$ can thus be written as (in SI units):

$$
F=F_{g}+F_{m}=\rho_{f} V g+\frac{1}{\mu_{0}} \kappa_{f} V_{f} B \nabla B
$$

where $\rho_{f}$ and $\kappa_{f}$ are the physical density and magnetic susceptibility of the magnetic fluid, respectively, $B$ is the induction of the applied magnetic field and $g$ is the acceleration of gravity. The gradient of the magnetic field $\nabla B$ is assumed to be along the vertical axis $z$, i.e. along the direction of separation. Equation (1) can be rewritten as:

$$
F=\left(\rho_{f}+\kappa_{f} \frac{B \nabla B}{\mu_{0} g}\right) V_{f} g
$$

The expression in parenthesis can be viewed as an apparent density of a medium exposed to an external non-homogeneous magnetic field and can be written as:

$$
\rho_{a}=\rho_{f}+\kappa_{f} \frac{B \nabla B}{\mu_{0} g}
$$




\subsection{Magnetic Fluids}

Magnetic fluids can be divided into two broad classes, namely solutions of paramagnetic salts and ferrofluids. Paramagnetic liquids are, as the name indicates, paramagnetic in their behaviour: their magnetisation increases linearly with an increasing magnetic field, and their magnetic susceptibility is low, as is shown in Table I.

In addition to a low magnetic susceptibility, some paramagnetic liquids tend to degrade in the presence of light; others tend to crystallize at lower temperatures, while others decompose at elevated temperatures. All such liquids are rather expensive and their recycling, though not easy, is thus imperative. The paramagnetic liquids often have a high surface tension and do not wet the particle surface adequately.

A ferrofluid, on the other hand, is a stable colloidal suspension of sub-domain magnetic particles in a carrier fluid. The particles, which have an average size of about $10 \mathrm{~nm}$, are coated with a stabilizing dispersion agent, which prevents particle agglomeration. Water, kerosene and oils are used as carrier liquids. When exposed to an external magnetic field, the ferrofluid becomes magnetised and reaches magnetic saturation at moderate magnetic fields. Equation (3) can then be rewritten as:

$$
\rho_{a}=\rho_{f}+\frac{J_{f}}{\mu_{0} g} \nabla B
$$

where $J_{f}$ is the magnetic polarization of the fluid.

It can be seen from Eq. (3) that, in order to achieve a constant apparent density of separation in a paramagnetic liquid, the product $B \nabla B$ must be constant. This is achieved by using an isodynamic field pattern. On the other hand, with ferrofluids, only the gradient of the magnetic field must be constant, assuming that the ferrofluid is magnetically saturated, as follows from Eq. (4). A comparison of the magnetic field strength and its gradient required achieving apparent densities of 2000 and $3500 \mathrm{~kg} / \mathrm{m}^{3}$ in a paramagnetic liquid and a ferrofluid is shown in Table II. This table also compares other characteristics of these two modes of separation. In order to achieve the required apparent density in a paramagnetic liquid, strong magnetic

TABLE I Typical physical properties of paramagnetic liquids and ferrofluids [1,2]

\begin{tabular}{lcccc}
\hline Magnetic fluid & Density $\left(\mathrm{g} / \mathrm{m}^{3}\right)$ & $\begin{array}{c}\text { Specific } \\
\text { magnetic } \\
\text { susceptibility } \\
\left(\left[\mathrm{m}^{3} / \mathrm{kg}\right] \times 10^{-7}\right)\end{array}$ & $\begin{array}{c}\text { Polarization } \\
\left([\mathrm{T}] \times 10^{-4}\right. \\
0.25 \mathrm{~T})\end{array}$ & $\begin{array}{c}\text { Saturation } \\
\text { polarization } \\
\left([\mathrm{T}] \times 10^{-4}\right)\end{array}$ \\
\hline $\begin{array}{c}\text { Saturated } \\
\text { solution } \\
\begin{array}{c}\mathrm{MnCl} \\
\text { MnCh }\end{array}\end{array}$ & $1450 \mathrm{H} \mathrm{H}_{2} \mathrm{O}$ & 5.9 & 2.2 & \\
$\begin{array}{c}\text { Saturated } \\
\text { solution } \\
\text { Mn( }\left(\mathrm{NO}_{3}\right) .4 \mathrm{H}_{2} \mathrm{O}\end{array}$ & 1650 & 5.8 & 2.4 & 470 \\
$\begin{array}{c}\text { Kerosene-based } \\
\text { ferrofluid }\end{array}$ & 1200 & $\approx 7550$ (initial, at 3 G) & $\approx 450$ & 180 \\
$\begin{array}{c}\text { Water-based } \\
\text { ferrofluid }\end{array}$ & 1400 & $\approx 3500$ (initial, at 3 G) & & 80 \\
\hline Magstream & 1170 & &
\end{tabular}


TABLE II Comparison of separation in paramagnetic liquids and ferrofluids

\begin{tabular}{|c|c|c|c|c|}
\hline \multirow[t]{2}{*}{ Parameter } & \multicolumn{2}{|c|}{ Paramagnetic liquid } & \multicolumn{2}{|c|}{ Ferrofluid, $J_{s}=0.0150 \mathrm{~T}$} \\
\hline & $\rho_{a}=2000 \mathrm{~kg} / \mathrm{m}^{3}$ & $\rho_{a}=3500 \mathrm{~kg} / \mathrm{m}^{3}$ & $\rho_{a}=2000 \mathrm{~kg} / \mathrm{m}^{3}$ & $\rho_{a}=3500 \mathrm{~kg} / \mathrm{m}^{3}$ \\
\hline Magnetic field (T) & 2.0 & 2.0 & 0.25 & 0.25 \\
\hline $\begin{array}{l}\text { Magnetic field } \\
\text { gradient }(\mathrm{T} / \mathrm{m})\end{array}$ & 10 & 25 & 0.8 & 2 \\
\hline $\begin{array}{l}\text { Maximum } \\
\text { apparent } \\
\text { density }\left(\mathrm{kg} / \mathrm{m}^{3}\right)\end{array}$ & \multicolumn{2}{|c|}{$\approx 3800$} & \multicolumn{2}{|c|}{$>20000$} \\
\hline Feed preparation & \multirow{3}{*}{\multicolumn{2}{|c|}{$\begin{array}{c}\text { Strongly and medium magnetic } \\
\text { material must be removed } \\
\text { Low } \\
\text { Several, as the separation density varies } \\
\text { along the vertical; poor selectivity }\end{array}$}} & \multirow{2}{*}{\multicolumn{2}{|c|}{$\begin{array}{c}\text { Only strongly magnetic material } \\
\text { must be removed } \\
\text { High }\end{array}$}} \\
\hline Selectivity & & & & \\
\hline $\begin{array}{l}\text { Number of } \\
\text { products of } \\
\text { separation }\end{array}$ & & & Two, or mc & , if required \\
\hline $\begin{array}{l}\text { Capital and } \\
\text { running costs }\end{array}$ & \multicolumn{2}{|c|}{ High } & \multicolumn{2}{|c|}{ Moderate } \\
\hline Fluid recycling & \multicolumn{2}{|c|}{ Difficult } & \multicolumn{2}{|c|}{ Straightforward } \\
\hline
\end{tabular}

field and very high field gradient must be employed. These requirements can be met only when powerful electromagnets with a narrow working gap are used. Very high capital and running costs and impossibility to scale up the technology are the major drawbacks of paramagnetic liquids. Considerable advantages of separation in ferrofluids (ferrohydrostatic separation or FHS) over separation in paramagnetic liquids are thus obvious.

\subsection{Cut-Point Density of Separation}

A particle suspended in a ferrofluid is acted upon by the force of gravity and two buoyancy forces. The first buoyancy force is the classical Archimedes gravityrelated force, and the other is the magnetically induced buoyancy force due to the magnetic 'weight' of the ferrofluid as introduced by Rosensweig [3] and expanded by Svoboda [2]. The effective cut-point density $\rho_{s p}$ can be defined as that particle density for which the net vertical force on a particle suspended in a ferrofluid is equal to zero. For non-magnetic particles the cut-point density can be written as:

$$
\rho_{s p}=\rho_{f}+\frac{J_{f}}{\mu_{0} g} \nabla B
$$

which is equivalent to Eq. (4).

The density of separation is thus uniquely determined and can be changed by adjustment of the magnetic field gradient and the concentration (and thus the magnetisation) of the ferrofluid. It has thus been shown that the loss of weight experienced by a particle suspended in a ferrofluid is determined by the generalized Archimedes law. The force of gravity acting on the fluid is aided by the magnetic traction force pulling the ferrofluid in the direction of the magnetic field gradient. Particles whose densities are smaller than the apparent density of the ferrofluid 
will float, while particles with density greater than the apparent density of the ferrofluid will sink.

\section{RECENT DEVELOPMENTS IN FERROHYDROSTATIC SEPARATION}

In view of the fact that FHS offers a unique technique for material manipulation, the range of potential applications is extensive. FHS technology is presently being used, on a limited industrial scale, for the recovery of gold and other platinum-group metals [4,5] and the treatment of diamond-bearing minerals [6]. On pilot-plant scale, FHS is being applied to the treatment of wastes and process tailings, electronic and automobile scrap, slags coal analysis and recovery of base metals [4,7].

In spite of the considerable potential of ferrohydrostatic separation, its wide-scale application is restricted for a variety of reasons. This includes the incorrect design of the magnetic circuit and shape of the pole tips, a lack of accurate density control, inefficient recovery of ferrofluid, the high cost of commercially available ferrofluids, and perceived environmental risk. This situation recently has changed significantly. Very selective separators, with automated density control, capable of treating a variety of materials in a wide spectrum of densities and particle sizes, have been developed by De Beers Consolidated Mines (Pty) Ltd [6]. Technology for the recovery of ferrofluids has been developed and low-cost ferrofluids are being manufactured on a production scale [6]. In contrast to conventional heavy liquids, these ferrofluids are inexpensive, non-toxic and can be easily recovered and recycled.

\subsection{Design of Selective Ferrohydrostatic Separators}

Ferrohydrostatic separators employ a magnetic field of a well-defined pattern to create a prescribed apparent density of the ferrofluid. For accurate separation of materials with a small density difference, a constant apparent density within the entire separation space is required. It follows from Eq. (5) that, in order to obtain a constant apparent density, the product $J_{f} \nabla B$ must be constant. It has always been assumed that the ferrofluid is magnetically saturated and thus $J_{f}=$ const. Under this assumption, the constant apparent density will be obtained if $\nabla B=$ const. Although practical shapes of the pole profiles were developed using conformal mapping techniques [8], their accuracy was found to be limited. Accurate profiles of the poletips were designed using finite-element electromagnetic modelling [1,6]. Such an optimization procedure not only produces a constant field gradient and therefore a constant separation density, but also allows relaxing the often-incorrect assumption that the ferrofluid is magnetically saturated.

In order to maintain accurate control of the apparent density, the separator requires a closed-loop control system. Any variation of the apparent density, caused, for instance, by variations in temperature or in the resistance of the magnet winding, will adversely affect the accuracy of cut-point density. It is therefore vitally important to monitor the density of the ferrofluid. This is achieved with the aid of a detection system, which detects any changes in the apparent density of the ferrofluid. The output of the detection system is used by a closed-loop controller to regulate the power supply output to maintain the ferrofluid at a constant apparent density. 


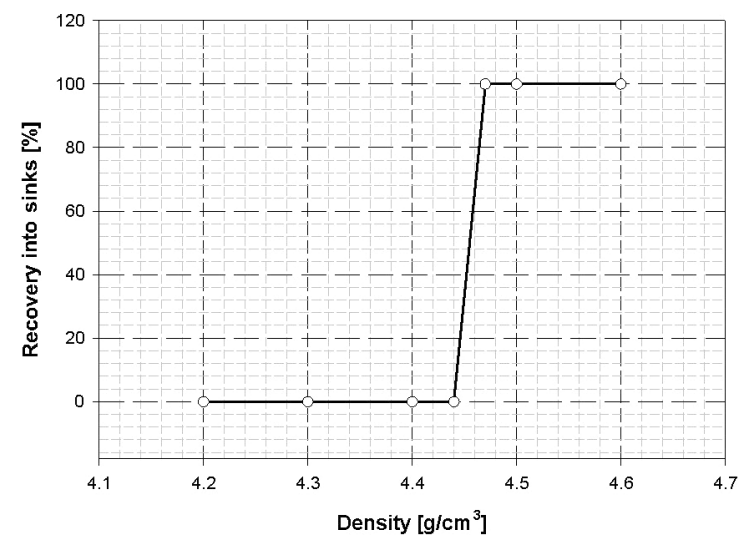

FIGURE 3 Typical Tromp curve for an FHS separator.

A combination of accurate design of the magnetic field pattern and continuous monitoring of the apparent density of the ferrofluid has allows the design and manufacture selective ferrohydrostatic separators. Such fully automated computercontrolled units are capable of treating particles in the size range $-25+0.3 \mathrm{~mm}$ and can distinguish a density difference of at least $20 \mathrm{~kg} / \mathrm{m}^{3}$ for particles of density $4400 \mathrm{~kg} / \mathrm{m}^{3}$. This corresponds to an $E<0.007$. A typical Tromp curve for such a separator is shown in Fig. 3. Units with a throughput of the order of $1 t / h$, depending on the feed density and size distribution, have been built.

\subsection{Application of Ferrohydrostatic Separation to Coal Fractionation}

As a result of the ability of FHS to separate materials into narrow, well-defined density fractions in a wide range of densities, using a single fluid density, which can be changed by varying the magnetic field strength, the technique is particularly suitable for densimetric analysis. Sink-float analysis of coal has been one of the areas of potential applications of FHS. Densimetric analysis of coal is usually carried out in bromoform and aqueous solutions of zinc chloride. Both heavy liquids are toxic and expensive to acquire and to dispose of. Such a hands-on operation, involving in several liquids, to cover the entire density region from 1800 to $2400 \mathrm{~kg} / \mathrm{m}^{3}$, is tedious and environmentally unfriendly. The obvious advantage of using magnetic fluids to separate coal into narrow density fractions has been appreciated, over the last 20 years, by numerous researchers and a wealth of information appeared on this subject in various journals and conferences. Although several publications have reported encouraging results, the image of FHS as a novel tool for coal fractionation was tarnished by studies which were based on an incorrect understanding of the variables that were critical for FHS, and inefficient or erroneous design of the separators.

Gubarevich [7] employed a ferrohydrostatic separator with hyperbolic pole-tips to investigate fractionation of coal. Kerosene-based ferrofluid was used and four size fractions of coal, ranging from 1 to $100 \mathrm{~mm}$, were introduced into the separator at feedrates from 50 to $400 \mathrm{~kg} / \mathrm{h}$, depending on particle size. The results, shown in Table III, were compared with densimetric analysis obtained with heavy liquids. It can be seen that while the best results were obtained in the coarse fractions 
TABLE III Comparison of densimetric analysis of coal in heavy liquids and FHS [8]

\begin{tabular}{lcc}
\hline Separation density $\left(\mathrm{kg} / \mathrm{m}^{3}\right)$ & $\begin{array}{c}\text { Size fraction }(\mathrm{mm}) \\
\text { Concentration of impurities in } \\
\text { FHS fractions (\%) with respect } \\
\text { to heavy liquids }\end{array}$ \\
\hline \multirow{2}{*}{100} & $-100+50$ & 0 \\
& $-50+25$ & 0 \\
1800 & $-25+13$ & 0.7 \\
& $-13+1$ & 1.8 \\
& $-100+50$ & 0 \\
& $-50+25$ & 0 \\
& $-25+13$ & 0.9 \\
\end{tabular}

TABLE IV Typical results of pilot-plant scale densimetric analysis of coal using FGS-2 [9]

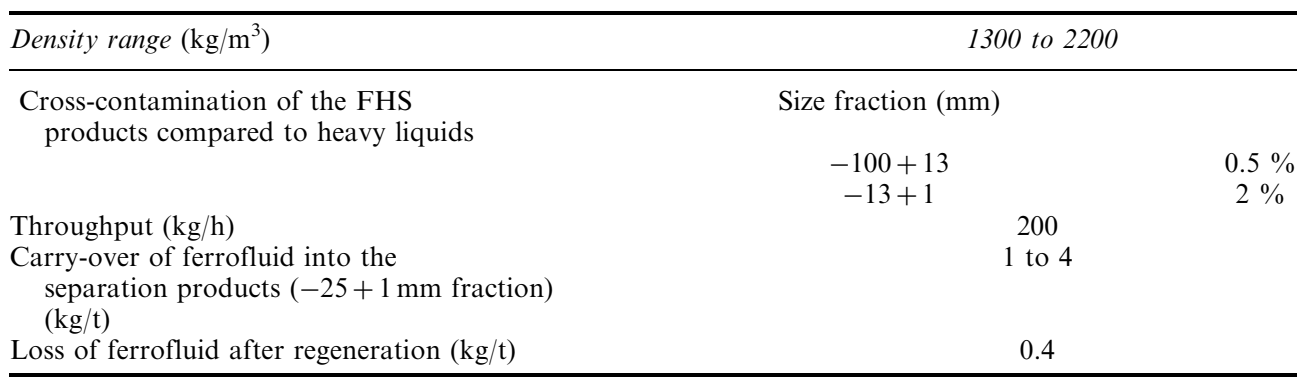

$(-100+50 \mathrm{~mm}$ and $-50+25 \mathrm{~mm})$, even in the $-25+13 \mathrm{~mm}$ and $-13+1 \mathrm{~mm}$ fractions the concentration of impurities in the FHS products was very low. The selectivity of separation was found to be high, with $E p$ ranging from 15 to $45 \mathrm{~kg} / \mathrm{m}^{3}$, depending on the ferrofluid density. The high accuracy of separation is assisted by the fact that most coals are very feebly magnetic (magnetic susceptibility being of the order of $2.5 \times 10^{-8} \mathrm{~m}^{3} / \mathrm{kg}$ ) [7]. It was also observed that chemical interaction between the ferrofluid and organic and mineral matter of the coal was negligible.

Based on the above experiments, a production-scale continuous FHS separator (FGS-2) was developed by the Gipromashugleobogaschenie Institute, Lugansk, Ukraine. This separator, shown in Fig. 3, underwent several pilot-plant tests, duration of each exceeding $600 \mathrm{~h}$. Typical results are summarized in Table IV. In spite of satisfactory performance, several attempts to commercialise this technology failed [9] as a result of geopolitical changes in the former USSR at that time.

Fujita et al. [10] described the design of a batch ferrohydrostatic separator for densimetric analysis of coal. Although the shape of the pole tips used in this separator did not generate a constant apparent density in the separation space, the results of coal fractionation, shown in Figs 4 and 5, were encouraging. The separation curves for three size fractions, namely $-25+13 \mathrm{~mm},-13+3.3 \mathrm{~mm}$ and $-3.3+0.3 \mathrm{~mm}$ were similar for both separation methods, namely FHS and zinc chloride. The carry-over of the water-based ferrofluid into the products of separation was less than $5 \mathrm{~kg}$ per ton of the feed material, in agreement with the value given by Gubarevich [7] (Table IV). Further regeneration of the ferrofluid reduced the loss to about $0.5 \mathrm{~kg} / \mathrm{t}$. 


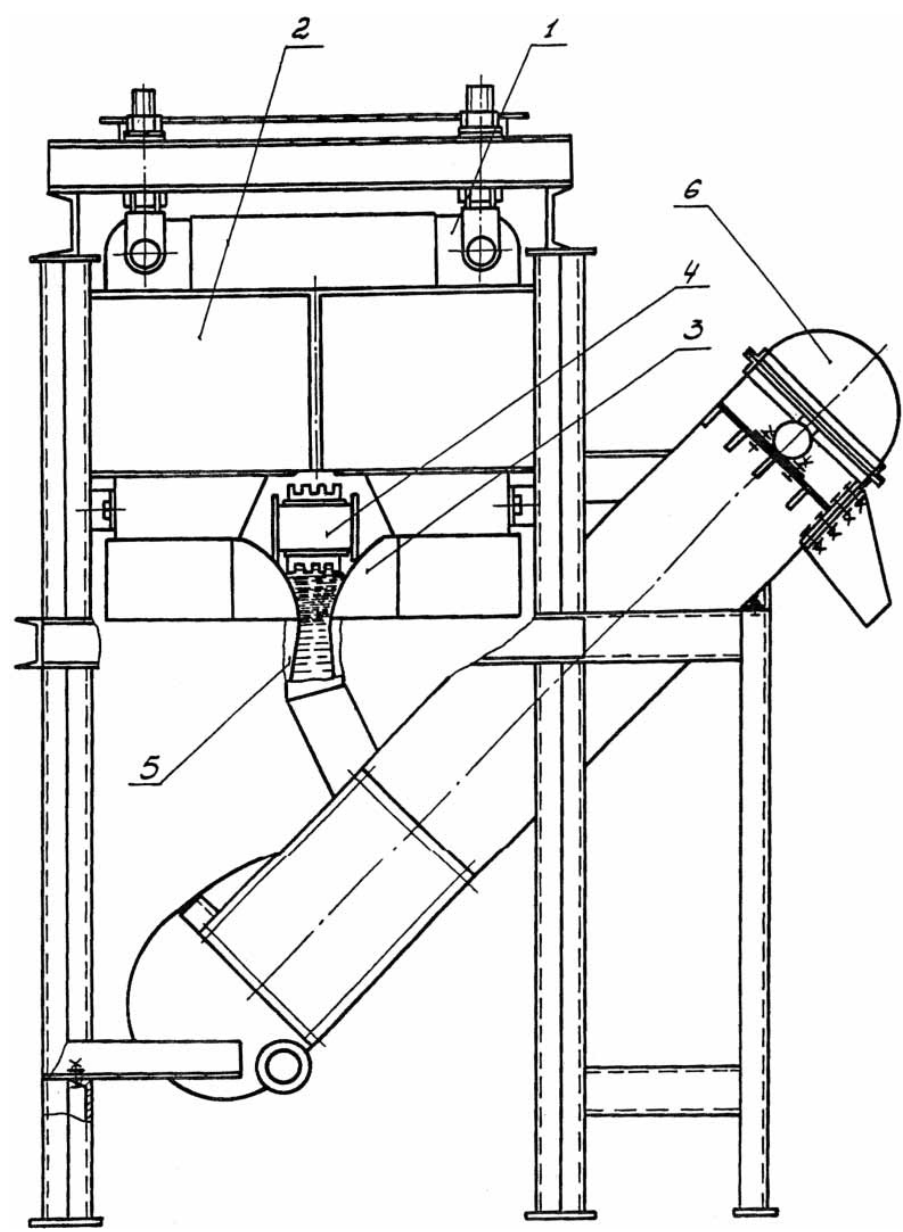

FIGURE 4 FGS-2 separator for fractionation of coal [9]. (1) electromagnet, (2) coils, (3) pole-tips, (4) hopper, (5) bottomless separation chamber with hydraulic support, (6) lift.

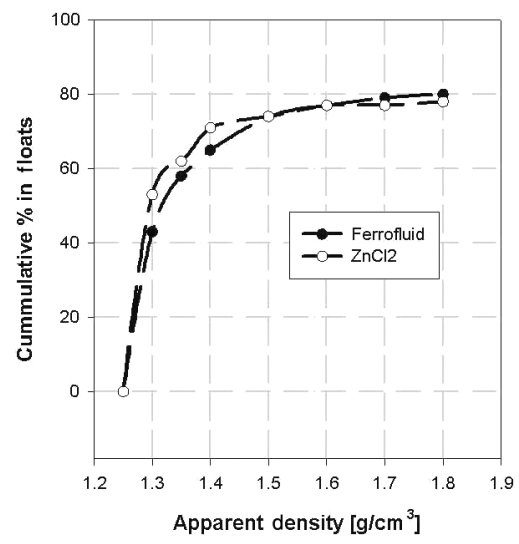

FIGURE 5 Comparison of densimetric analysis of coal using FHS and $\mathrm{ZnCl}_{2}$ [10]. Particle size: $-25+13 \mathrm{~mm}$. 


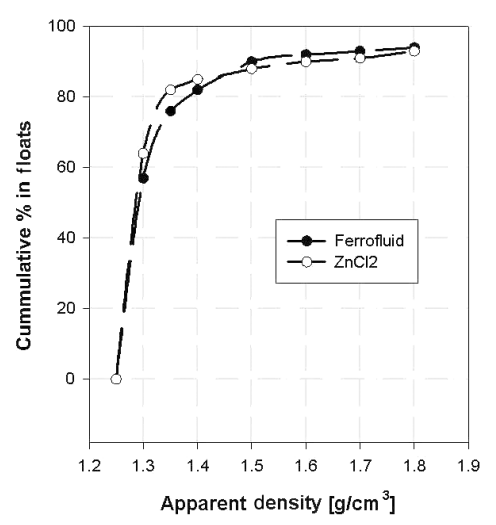

FIGURE 6 Comparison of densimetric analysis of coal using $\mathrm{FHS}$ and $\mathrm{ZnCl}_{2}$ [10]. Particle size: $-3.3+0.3 \mathrm{~mm}$.

Ferrohydrostatic separation of brown coal using a continuous separator with wedge-shaped pole-tips was investigated in Slovakia [11]. Various size fractions ranging from 0.1 to $20 \mathrm{~mm}$ were treated in a water-based ferrofluid in the density range from 1200 to $2200 \mathrm{~kg} / \mathrm{m}^{3}$. Although comparison with heavy liquids was not made, it was concluded that FHS is a suitable technique for densimetric analysis of coal. Unconvincing results were reported by Fofana and Klima [12]. The batch separation of fine fractions $(-3+0.15 \mathrm{~mm})$ coal was carried out by immersing the coal samples in a water-based ferrofluid for one hour before the separation products were collected. The ferrofluid was thus allowed to selectively adsorb onto different components of coal, affecting thus their apparent densities. The results were also negatively influenced by the fact that a step-wise profile of the pole-tips was used. Therefore, the apparent density of the ferrofluid was not constant within the separation space, which resulted in further misplacement of the components of coal.

\section{FUTURE OF FHS AS APPLIED TO COAL FRACTIONATION}

Ferrohydrostatic separation of coal possesses numerous advantages compared to many other applications. Most components of coal are generally very weakly magnetic and their density does not change when they are introduced into a ferrofluid placed in a non-homogeneous field. The density distribution of coal thus obtained is essentially identical to the true physical density distribution. Furthermore, the analysis is usually conducted on particles greater than $0.5 \mathrm{~mm}$. For such sizes the effect of the hydrodynamic drag on particles is negligible and the value of the apparent density of the ferrofluid is not affected. The accuracy and selectivity of densimetric analysis of coal by FHS is therefore, from first principles, high.

On the other hand, there are specific issues that require special attention. Fractionation of coal is usually conducted in the density range from 1200 to $2200 \mathrm{~kg} / \mathrm{m}^{3}$. These densities are rather low and in order to achieve them in FHS, a low magnetic field gradient and/or weakly magnetic ferrofluid must be used, as can be seen in Table II. Under these conditions it is rather difficult to contain the ferrofluid in the separation space, as a result of the weak magnetic force that holds the ferrofluid 
within the magnet. This is clearly not a problem in FHS units that operate in a batch mode $[10,12]$ and use enclosed separation chambers. However, in a continuous operation, which requires continuous removal of the products of separation, measures must be taken to retain the fluid in the separation chamber. The FGS-2 separator [9] used an inclined, bottomless separation chamber, which allowed continuous removal of the sink and float fractions. In order to retain the ferrofluid in the chamber, hydraulic support using a water column was employed [7,9], as can be seen in Fig. 4. A completely general FHS technique that allows the separation of materials of even very low densities, without resorting to complicated methods of ferrofluid retention, has been recently proposed by Svoboda [13].

One of the main restrictions in the application of FHS to coal fractionation is the limited size of the separation space. A particle size of $25 \mathrm{~mm}$ requires a gap of at least $75 \mathrm{~mm}$ at the narrowest point of the separation space. For correctly shaped pole-tips, which would ensure a constant apparent density of the ferrofluid, this dictates a gap width at the feed point of at least $220 \mathrm{~mm}$. It is possible, however, to obtain the required magnetic field and the apparent density of the ferrofluid, even in such a large volume, and separators that meet such specifications have been built $[6,9,14]$.

It is, therefore, apparent that currently available continuous ferrohydrostatic separators allow selective densimetric analysis of materials with particle sizes up to $25 \mathrm{~mm}$, in a wide density range at the feedrates as high as $1 t / h$. The residence time of material to be separated is several seconds in these separators. In contrast to batchtype fractionation, the continuous mode of operation eliminates the possibility of excessive adsorption of the ferrofluid onto the particles and thus the negative effect of possible chemical reaction. The detrimental effect of the absorbed ferrofluid on the magnetic properties and thus on their apparent density is also excluded.

Although the accuracy of densimetric analysis using conventional of ferrohydrostatic separators illustrated in Figs. 1 and 2 is satisfactory, further improvement can be obtained by a more sophisticated design of the magnetic system. As a result of the presence of pole-tips in an FHS based on the design shown in Fig. 2, the apparent density of the ferrofluid is constant only in a limited region at the centre of the separation chamber. This phenomenon reduces not only the accuracy of separation, but also the throughput and the maximum particle size than can be treated by the separator. To obtain the required magnetic field, a constant field gradient and a constant apparent density of the ferrofluid in a large volume, an iron-clad solenoid [15] or C-type magnet [16] can be used. Figures 7 and 8 illustrate embodiments of principles based on the iron-clad solenoid and the C-magnet concept, respectively. The endeffects of the pole-tips are eliminated and scale-up is accomplished by merely increasing the width of the magnet. The length of the air gap, an important determinant of the magnet cost and energy consumption remains constant. C-type magnets of a large width and iron-clad solenoids of a large diameter can be built and large-capacity separators can, therefore, be designed.

\section{CONCLUSION}

Ferrohydrostatic separators can be used as accurate tools for densimetric analysis of coal. Several experimental programmes and pilot-plant tests have shown that FHS 


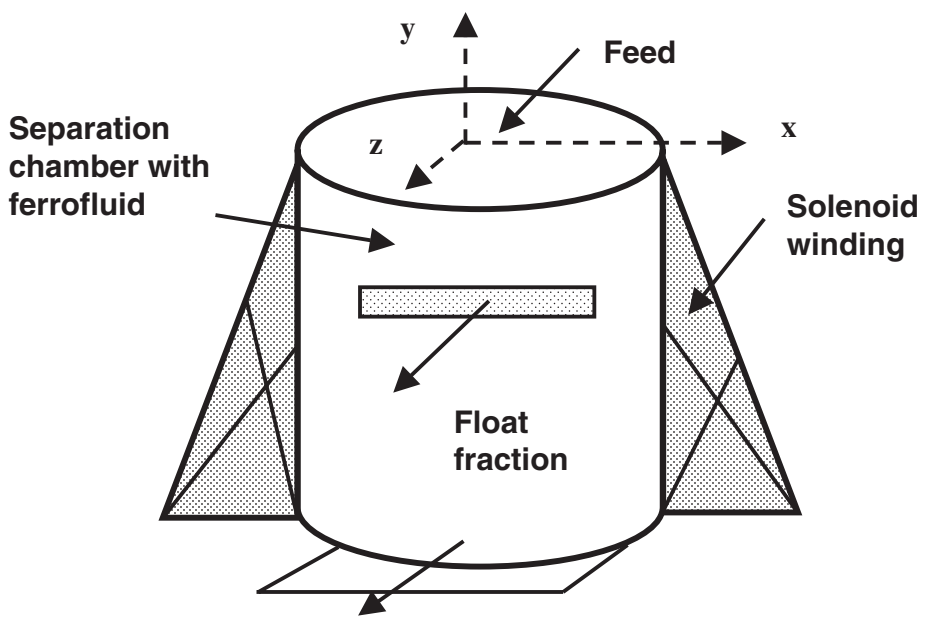

Sink fraction

FIGURE 7 Schematic diagram of a ferrohydrostatic separator with a solenoid magnet [15].

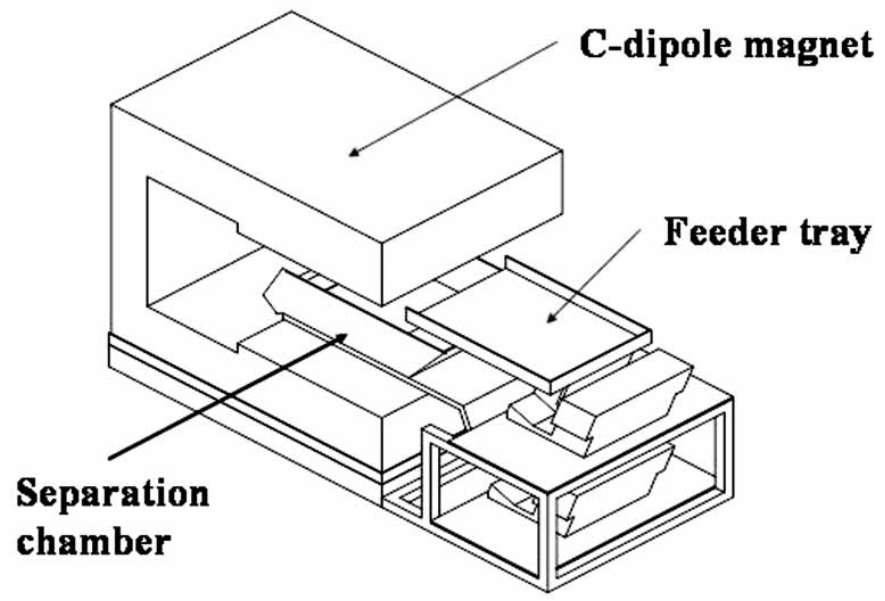

FIGURE 8 Schematic diagram of a large-scale FHS separator based on C-pole magnet design [16].

can be as accurate as separation by heavy liquids while the cost, complexity of operation and environmental hazards are reduced. Moreover, ferrohydrostatic separators lend themselves to automation, the rate of sample treatment is high and the detrimental effect of chemical and physical interaction of the heavy liquids with the coal matter is reduced. Further development of FHS technology is likely to result in more accurate and large-scale equipment for coal fractionation.

\section{References}

[1] J. Svoboda, Magnetic Techniques for the Treatment of Materials, Kluwer Academic Publishers, Dordrecht, 2004. 
[2] J. Svoboda, Separation of materials in magnetic fluids: principles, applications and the future developments. In: Proceedings International. Symposium on Waste Processing and Recycling in Mineral and Metallurgical Industries III, Calgary, Canada. S.R. Rao, L.M. Amaratunga, G.G. Richards and P.D. Kondos (Eds), The Canadian Institute of Mining, Metallurgy and Petroleum, Montreal, 1998, pp. 31-46.

[3] R.E. Rosensweig, Buoyancy and stable levitation of a magnetic body immersed in a magnetisable fluid, Nature, 120 (1966), 6.

[4] A.B. Solodenko, Personal communication (1996).

[5] R.D. Smolkin, V.S. Krohmal and O.P. Sayko, Commercial equipment designed to recover gold from gravitational concentrates by means of magnetic separation and separation in magnetic fluids. In: Proc. XVIII International Mineral Processing Congress, Sydney, Australia, The Australasian Institute of Mining and Metallurgy, Melbourne, 1993, pp. 425-431.

[6] J. Svoboda, Separation in magnetic fluids: time to meet the technological needs, In: Proceedings MINPREX 2000 Conference, Melbourne, The Australasian Institute of Mining and Metallurgy, Carlton, 2000, pp. 297-301.

[7] V.N. Gubarevich, Separation of Materials in Magnetic Fluids, Nedra, Moscow (in Russian) 1987.

[8] V.V. Gogosov, R.D. Smolkin, Yu.M. Garin, O.P. Sayko and V.S. Krokhmal, Some features of calculations of separators with magnetic fluids, J. Inst. Phys. Acad. Nauk Latv. SSR 3 (1984), 191-194 (in Russian).

[9] V.N. Vlasov, Personal communication (1996).

[10] T. Fujita, S. Mori, M. Mamiya and J. Shimoiizaka, An improved sink-float testing apparatus for coal preparation using a water-based magnetic fluid, In: Proc. 11th International Coal Preparation Congress, Tokyo 1990, The Mining and Materials Processing Institute of Japan, Tokyo, 1990, pp. 109-114.

[11] M. Lovas, S. Jakabsky, A. Mockovciakova, S. Hredzak and L. Turcaniova, Utilization of ferrofluids in brown coal preparation, In: Innovation in Mineral and Coal Processing, Atak, Onal and Celik (Eds), Balkema, Rotterdam, 1998, pp. 367-372.

[12] M. Fofana and M.S. Klima, Magnetic-fluid separations of coal using a modified Frantz electromagnet, Coal Prep., 18 (1997), 91-114.

[13] J. Svoboda, Ferrohydrostatic separation method and apparatus for separation of low density materials, Patent pending (2004).

[14] V.N. Gubarevich and S.V. Vidsota, Theoretical principles, present status and prospects for development of material separation in magnetic fluids, Magn. Electr. Sep., 5 (1994), 169-192.

[15] J. Svoboda, Ferrohydrostatic separation method and apparatus, US Patent 6,026,966 (2000).

[16] J. Svoboda, Ferrohydrostatic separation method and apparatus, European Patent 4-231 (2001). 